\title{
CULTURAL HERITAGE AND URBAN LANDSCAPE IN A FUTURE EUROPEAN CULTURAL CAPITAL - CHALLENGES AND TRENDS
}

\author{
ATALIA ONITIU, MARIANA BALACI \\ Faculty of Sociology and Psychology, West University of Timișoara, Romania
}

(C) 2020 Atalia Onițiu, Mariana Balaci

This is an open access article distributed under the Creative Commons Attribution-NonCommercial-NoDerivs license (http://creativecommons.org/licenses/by-nc-nd/3.0/)

DOI: $10.1515 /$ eras-2020-0010

\begin{abstract}
European countries interest for archaeological heritage, as part of the cultural landscape, was firstly expressed at the London Convention (1969), whose content was later revised by La Valetta Convention (1992). Romania joined this Convention in 2000, thus assuming the mission to protect and preserve the archaeological heritage, facing with massive economic development and urban expansion. Although we speak of a consecrated historical center, in Timisoara's urban landscape preventive archaeology has become a reality only from 2004, when first researches were conducted. During the last few years, local infrastructure development has determined an extension of archaeological investigations over the historical area of the city, with major influences especially over public transportation (most of the times hampered, sometimes deviated, even blocked in the specific area, during archaeological research). Our approach focuses on multiple facets and implications of preventive archaeology over Timisoara's urban landscape, from immediate, obvious issues (such as population's satisfaction regarding archaeological investigations, their consequences (over access in the area, safety or transportation)), to long-term results (over local tourism, urban development or locals' education for protecting and promoting cultural heritage).
\end{abstract}

\section{Keywords}

cultural heritage, preventive archeology, urban development, infrastructure, impact

\section{Introduction}

Cultural heritage represents the whole corpus of material signs - artistic or symbolic passed down from the past within each culture. Having a spatio-temporal character, it refers both to what is human and related to the environment, both architectural complexes and archaeological sites, including rural heritage (traditions, techniques, social practices, rituals, holidays), but also urban, technical or industrial, street furniture or construction.

Cultural heritage in all its forms, material or immaterial, movable or immovable, is a legacy of human society. It sums up a multitude of achievements of past generations that have been preserved until now and that we have a moral obligation to pass on to future generations. In order to be able to carry out this duty, it is necessary to first recognize, research, protect and highlight all these elements that constitute the national and even international cultural heritage. Cultural heritage is a major asset of Europe and is an important component of the European project, helping to define European identity. Cultural heritage also contributes to the elimination of social disparities, facilitates social inclusion and participates in the cultural and social life of a society. Cultural heritage as a whole can be seen as a promoter of diversity and intercultural dialogue. 
Cultural heritage has deteriorated in recent years as a result of industrialization, accelerated urbanization, rising pollution levels, various climatic factors or excessive tourism. At the same time, however, awareness of the importance of cultural heritage has increased, the number of people visiting buildings or architectural complexes has increased, there have been associations defending heritage, even cultural policies on heritage.

At European level, the first steps towards emphasizing the importance of preserving cultural heritage have been taken since 1969, with the London Convention for the Protection of the Archaeological Heritage. A significant step was the Valletta Convention on the Protection of the Archaeological Heritage (1992), which emphasized the importance of archeology, and especially of preventive archeology, in the process of long-term urban evolution and in the writing of urban history.

Since 1992 (Declaration on Environment and Development, Rio de Janeiro), cultural heritage has become part of sustainable development. Concerns have arisen for the development of cultural tourism, for providing the necessary resources for the conservation of cultural heritage, for adapting the functionality of cultural heritage, so that it can be integrated into the human or natural environment and the living culture of the community.

Cultural heritage is a concern in Romania only in the last three decades. Thus, only on March 30, 1990, Romania adopted the UNESCO Convention on the Protection of Cultural and Natural Heritage (November 16, 1972). The first law on Mobile National Cultural Heritage was drafted on October 25, 2000 and republished on April 9, 2014. To these are added other documents of utmost importance, namely the Sectoral Strategy for Culture and National Heritage (2014-2020) and the Strategy for Culture and National Heritage (2016-2020). Regarding preventive archeology, in Romania there was no law until 2000 (GD 43 / 31.01.2000 on the Protection of Archaeological Heritage and the Declaration of Archaeological Sites as Sites of National Interest), although Romania acceded to the La Valletta Convention in 1997. In 1999 the Archaeology Service was established, later (2001-2003) the Archaeology Department and in 2003 the Museum and Historical Monuments Directorate. In 2000, the National Commission of Archaeology was established, and in 2009 the National Institute of Heritage (which includes cIMEc, which has been operating since 1990).

Regarding the preventive archaeological researches carried out in recent years in Timisoara, we can say that they were carried out because our legislation requires such research, when a reorganization of the city's infrastructure takes place, or interventions take place at ground level in protected areas or areas of protection of archeological sites or other historical monuments.

Among the most well-known preventive archeological researches in Timişoara we mention:

1. the preventive archaeological research from 2006 carried out on the occasion of the rehabilitation works of the tramway infrastructure in the historical area of Timişoara (Street 9 Mai, Liberty Square, St. George Square); on this occasion, a series of wooden houses belonging to the Ottoman period were discovered;

2. the preventive archaeological research from 2013 carried out on the occasion of the construction of the last building of the City Business Center complex (building E); on this occasion, the dam of the Austrian fortification of Timișoara was discovered, a singular construction so far in the archeological landscape of Timissoara; fortunately, through the involvement of archaeologists and the public-private partnership, this dam was rebuilt on a small scale in the discovery area and can be visited today.

3. the preventive archaeological research from 2013-2014 that took place in Liberty Square, St. George Square, Union Square and 10 other streets in the historic center on the occasion of the rehabilitation project of the historic center of the city and the transformation of 
a series of streets into pedestrian spaces; on this occasion one of the main mosques of the city, the Turkish bath, but also a series of public or private buildings belonging to the Ottoman era were discovered; some of these discoveries were highlighted at the pavement level, and part of the mosque in St. George's Square has been restored;

4. the archaeological research from 2017 that took place on Popa Șapcă Street on the occasion of the rehabilitation of the taxiway on this street; component elements of the bastion fortress of Timişoara were highlighted;

5. the preventive archaeological research from 2018 that took place in Marasti Square, Street Calea Aradului, Street Oituz, Street G. Dima; on this occasion the Vienna Gate appeared, one of the gates of the Austrian fortress that surrounded Timisoara; so far no marking of this important archaeological discovery has been made;

6. the preventive archaeological research from 2019 that took place at the Cardinal Points, Martin Luther Street on the occasion of expanding the number of traffic lanes from 2 to 3; component elements of the Austrian fortress appeared.

\section{Methodology}

This approach aims to present the data obtained from a sociological survey conducted in the city of Timisoara over three years (July-September 2018, November-December 2019 and May-June 2020), on a total of 863 subjects (53 in 2018, 154 in 2019 and 657 in 2020). The subjects come from among the permanent residents and non-residents of the city of Timişoara (residents and visitors). Their selection was done randomly, using the snowball method.

As characteristics of the studied population, in terms of gender distribution there were 22 male and 31 female subjects (2018); 71 males and 81 females (2019) and 274 males and 381 females (2020), in total over the entire period studied 367 males (42.5\%) and 493 females (57, $5 \%$ ), a situation we would say relatively balanced between the two categories.

As a level of education, in 2018 the subjects had attended: high school (3), university studies (31) and postgraduate studies (18). In 2019: general school (1), high school (44), university studies (78) and postgraduate studies (14). In 2020, general school (15), high school (209), university studies (332) and postgraduate studies (32). It is thus found that the majority of respondents have a university degree $(51.1 \%)$, followed by those with secondary education $(29.6 \%)$.

By age categories, the situation of the subjects is as follows:

\begin{tabular}{|l|r|r|r|}
\hline & $\mathbf{2 0 1 8}$ & $\mathbf{2 0 1 9}$ & $\mathbf{2 0 2 0}$ \\
\hline 19-30 years & 17 & 117 & 529 \\
\hline 30-40 years & 8 & 10 & 49 \\
\hline 40-50 years & 15 & 11 & 45 \\
\hline 50-60 years & 9 & 5 & 13 \\
\hline Over 60 years & 3 & 2 & 5 \\
\hline
\end{tabular}

It can be seen that the young population predominates, in an overwhelming majority, which leads us to appreciate that our study captured, without having this initial intention, the perspective of young people, which is, here and everywhere, the future of this city.

Regarding the area of residence, most of the subjects stated that they live in Timișoara (39/117/442, ie a total of 598 respondents, representing $69.3 \%$ of the total population studied). Out of the total respondents, 762 stated that they visited the city several times, which represents $88.3 \%$ of the total subjects.

The objective pursued in our research did not require the establishment of a sample, the subjects can be permanent residents, temporary residents or simple visitors to the city. The tool 
used was the questionnaire, and the application of the questionnaires was done both face to face and in the online environment. The questionnaire was structured in the form of 15 questions (open, closed, Likert scale), to which were added 7 factual questions.

\section{Results}

The main objective of our research was to make a diagnosis of the existing state of affairs in the city of Timisoara, the future European cultural capital (initially in 2021, later the deadline being postponed to 2023 due to the coronavirus pandemic), in which regarding the preventive archeology, the impact it has in the short term on the inhabitants of the city and in the long term on the urban development, the interest for the safeguarding of the cultural heritage and for the sustainable development both from the civic involvement and from the local authorities.

At the national level, preventive archaeological research has gained momentum in the last decade, as a result of investments made in infrastructure works. Since 2010, 3977 preventive archeological researches have been carried out on the Romanian territory. At the level of Timiş County, for the same period of time, 190 researches were registered (approximately $4.7 \%$ ), and in the city of Timișoara 80 (representing $2.01 \%$ of the national researches and $42.10 \%$ of those carried out at the level of county), a reality far below our expectations.

In the period 2018-2020 (the period of our research), at the national level, 1914 preventive archeological researches were carried out, while at the level of Timiș County 92 $(4.80 \%)$. If in 2018 in the city of Timisoara were organized 9 preventive archaeological research, in 2019 there were 12, and in 2020 - 10 (based on the number of authorizations issued by the Ministry of Culture - Romanian Archaeological Research Management System). With a total of 31 archaeological researches, the city of Timissoara represents only $1.62 \%$ of the total national researches, respectively $33.6 \%$ of the total researches at county level.

Carrying out a relatively small number of archaeological research could have two scenarios in terms of consequences: either a good knowledge and familiarization of the inhabitants and visitors of the city with these researches (due to their unique and unusual character), or, on the contrary, a poor knowledge due to their small number). Thus, a first objective of our research was to investigate whether and to what extent the inhabitants and / or visitors of the city of Timisoara are familiar with the preventive archaeological research carried out in the city in recent years. The first research hypothesis that we followed in our study was that the inhabitants and visitors of the city of Timisoara have knowledge about the preventive archaeological research carried out in the city area. To validate this hypothesis, several questions were asked in the questionnaire: Q1. Do you know the fact that in Timişoara there have been archeological researches in recent years that have targeted objectives from the area of historical Timişoara? Q2. According to Ordinance no. 43/2000, any infrastructure work carried out in an area with archaeological objectives implies the obligation to discharge the archaeological load. Do you know this fact?; Q4. Where have archeological researches taken place in Timisoara in recent years?

The situation of the last three years regarding the answers of the subjects to questions Q1 and Q2 has been summarized in the table below.: 


\begin{tabular}{|c|c|c|c|c|c|c|c|c|c|c|}
\hline \multirow[b]{3}{*}{ Year } & \multicolumn{5}{|c|}{ Q1 } & \multicolumn{5}{|c|}{ Q2 } \\
\hline & \multirow{2}{*}{$\begin{array}{c}\text { Valid } \\
\text { answers }\end{array}$} & \multicolumn{2}{|c|}{ Yes } & \multicolumn{2}{|c|}{ No } & \multirow{2}{*}{$\begin{array}{c}\text { Valid } \\
\text { answers }\end{array}$} & \multicolumn{2}{|c|}{ Yes } & \multicolumn{2}{|c|}{ No } \\
\hline & & Nr. & $\%$ & Nr. & $\%$ & & Nr. & $\%$ & Nr. & $\%$ \\
\hline 2018 & 51 & 46 & 90,2 & 5 & 9,80 & 51 & 38 & 74,5 & 13 & 25,5 \\
\hline 2019 & 132 & 90 & 68,2 & 42 & 31,8 & 127 & 50 & 39,3 & 77 & 60,7 \\
\hline 2020 & 568 & 373 & 65,6 & 195 & 34,4 & 554 & 260 & 46,9 & 294 & 53,1 \\
\hline
\end{tabular}

It can be seen from the analysis of the answers that if the question Q1. Do you know the fact that in Timişoara archeological researches have taken place in the last years that aimed at objectives from the area of historical Timişoara? most of the answers in the three years are in the affirmative, with regard to question Q2. According to Ordinance no. 43/2000, any infrastructure work carried out in an area with archaeological objectives implies the obligation to discharge the archaeological load. Do you know this fact? there is a decreasing trend, expressed by the increase in the number of negative answers, inversely proportional to the affirmative ones. In other words, the level of knowledge of the population regarding the legislative provisions regarding preventive archeology and the relationship between them and constructive activities, including those carried out by individuals, is in a significant decrease. This situation, practically ignorant of those reasons that determine and require the development of preventive archaeological research, can have major consequences not only on (as we will see below) the level of satisfaction of citizens with this research, but can be a factor with a negative impact on the legal steps to safeguard the cultural heritage.

To these results are added the answers given to question Q4. Where have archeological researches taken place in Timișoara in recent years? Surprisingly and unexpectedly, if in 2018 only 5 subjects answered this question "I don't know" (given that we recorded 46 affirmative answers to question Q1), in 2019 - 79 respondents answered "I don't know" "(Compared to 90 affirmative answers in Q1), because in 2020, out of 657 subjects - 336 (ie 51.2\%) answered" I don't know "(provided that 373 answered" yes "in Q1 ).

Therefore, we are of the opinion that our first research hypothesis (H1. Residents and visitors of Timișoara have knowledge about preventive archaeological research carried out in the city area) is not validated. If the answers given to question Q1 were such as to suggest confirmation of the hypothesis, the in-depth question Q4 confirms the opposite. The answers given to question Q2 also lead us to this conclusion, which suggests a certain lack of interest on the part of citizens in terms of preventive archaeological research.

The second objective of the research was the impact of preventive archaeological research on the city in order to identify the degree of satisfaction of the subjects with the way in which this research was conducted. The research hypotheses in this case were: $\mathrm{H} 2$. The inhabitants and visitors of the city of Timișoara have a low level of satisfaction with the way in which the archaeological researches have been carried out so far and $\mathrm{H} 3$. There is an association between the level of education of the subjects and the level of satisfaction with the preventive archaeological research in the city of Timisoara).

In order to investigate the level of satisfaction of the subjects regarding the archaeological research, the following questions were included in the questionnaire: Q5. How satisfied are you with the way the archeological research was carried out?; Q10. Are you satisfied with the importance that local authorities attach to archaeological discoveries?; Q13. How satisfied are you with the information provided in the media during the conduct of preventive archaeological research?; Q14. How satisfied are you with the existing information on the spot regarding the archeological objectives discovered in the field?; Q15. Are you 
satisfied with the way in which the archeological objectives in Timișoara were restored and capitalized?

The situation over the three years subject to our research to each of the above questions was summarized as follows:

Q5. How satisfied are you with the way the archeological research was carried out??

\begin{tabular}{|l|r|r|r|r|r|r|}
\hline Year & $\begin{array}{c}\text { Valid } \\
\text { Answers }\end{array}$ & \multicolumn{1}{c|}{$\begin{array}{c}\text { Very } \\
\text { unsatisfied }\end{array}$} & \multicolumn{1}{c|}{ Unsatisfied } & \multicolumn{1}{|c|}{$\begin{array}{c}\text { Neither unsatisfied, } \\
\text { nor satisfied }\end{array}$} & Satisfied & \multicolumn{1}{c|}{$\begin{array}{c}\text { Very } \\
\text { satisfied }\end{array}$} \\
\hline $\mathbf{2 0 1 8}$ & 53 & 6 & 7 & 20 & 11 & 9 \\
\hline $\mathbf{2 0 1 9}$ & 153 & 4 & 19 & 85 & 33 & 12 \\
\hline $\mathbf{2 0 2 0}$ & 657 & 32 & 56 & 304 & 134 & 131 \\
\hline
\end{tabular}

The frequency analyzes recorded at the level of the three years present the same situation: most subjects answered this question with "neither dissatisfied nor satisfied", an answer with a certain degree of ambiguity, but clarified by the analysis of average frequencies, which in all three years is at a level above 3, with an upward trend (from 3.19 in 2018, to 3.20 in 2019, to 3.42 in 2020).

Q10. Are you satisfied with the importance that local authorities attach to archaeological discoveries??

\begin{tabular}{|c|r|r|r|r|r|r|}
\hline Year & $\begin{array}{c}\text { Valid } \\
\text { Answers }\end{array}$ & $\begin{array}{c}\text { Very } \\
\text { unsatisfied }\end{array}$ & Unsatisfied & $\begin{array}{c}\text { Neither unsatisfied, } \\
\text { nor satisfied }\end{array}$ & \multicolumn{1}{c|}{ Satisfied } & \multicolumn{1}{c|}{$\begin{array}{c}\text { Very } \\
\text { satisfied }\end{array}$} \\
\hline $\mathbf{2 0 1 8}$ & 53 & 13 & 19 & 12 & 6 & 3 \\
\hline $\mathbf{2 0 1 9}$ & 153 & 9 & 34 & 79 & 29 & 2 \\
\hline $\mathbf{2 0 2 0}$ & 657 & 62 & 121 & 257 & 114 & 103 \\
\hline
\end{tabular}

If in the first two years the average frequencies of 2.38 and 2.88 suggest a negative level of satisfaction of the subjects, in 2020 it increases, reaching 3.11. If in the first year we registered a number of 32 subjects $(60.3 \%)$ dissatisfied with the involvement of the authorities, their percentage registers a considerable and progressive decrease in the following years $(28.10 \%$ in $2019,27.85$ in 2020).

Q13. How satisfied are you with the information provided in the media during the conduct of preventive archaeological research?

\begin{tabular}{|c|c|r|r|r|r|r|}
\hline Year & $\begin{array}{c}\text { Valid } \\
\text { Answers }\end{array}$ & $\begin{array}{c}\text { Very } \\
\text { unsatisfied }\end{array}$ & Unsatisfied & $\begin{array}{c}\text { Neither unsatisfied, } \\
\text { nor satisfied }\end{array}$ & Satisfied & $\begin{array}{c}\text { Very } \\
\text { satisfied }\end{array}$ \\
\hline $\mathbf{2 0 1 8}$ & 53 & 14 & 18 & 13 & 4 & 4 \\
\hline $\mathbf{2 0 1 9}$ & 153 & 18 & 44 & 64 & 25 & 2 \\
\hline $\mathbf{2 0 2 0}$ & 657 & 102 & 149 & 212 & 104 & 90 \\
\hline
\end{tabular}

Regarding the media coverage of preventive archaeological research in Timisoara, the level of satisfaction here also increases slightly, from 2.36 in 2018, to 2.67 in 2019, to 2.89 in 2020 . Despite this upward trend, the negative responses of the subjects suggest a level low media involvement, possibly a determining factor in the low level of knowledge that subjects have about the exact location of such research in the city area. 


\section{Q14. How satisfied are you with the existing information on the spot regarding the archeological objectives discovered in the field?}

\begin{tabular}{|c|r|r|r|r|r|r|}
\hline Year & $\begin{array}{c}\text { Valid } \\
\text { Answers }\end{array}$ & $\begin{array}{c}\text { Very } \\
\text { unsatisfied }\end{array}$ & Unsatisfied & $\begin{array}{c}\text { Neither unsatisfied, } \\
\text { nor satisfied }\end{array}$ & Satisfied & \multicolumn{1}{|c|}{$\begin{array}{c}\text { Very } \\
\text { satisfied }\end{array}$} \\
\hline $\mathbf{2 0 1 8}$ & 53 & 15 & 15 & 13 & 7 & 3 \\
\hline $\mathbf{2 0 1 9}$ & 153 & 14 & 34 & 66 & 34 & 5 \\
\hline $\mathbf{2 0 2 0}$ & 657 & 61 & 121 & 251 & 130 & 94 \\
\hline
\end{tabular}

The level of satisfaction of the subjects increases from the negative quotas from the first years ( 2.40 in 2018 and 2.88 in 2019) to the situation of 2020, when an average of 3.11 frequencies is registered.

Q15. Are you satisfied with the way in which the archeological objectives in Timișoara were restored and capitalized??

\begin{tabular}{|l|r|r|r|r|r|r|}
\hline Year & $\begin{array}{c}\text { Valid } \\
\text { Answers }\end{array}$ & \multicolumn{1}{|c|}{$\begin{array}{c}\text { Very } \\
\text { unsatisfied }\end{array}$} & Unsatisfied & $\begin{array}{c}\text { Neither unsatisfied, } \\
\text { nor satisfied }\end{array}$ & Satisfied & \multicolumn{1}{c|}{$\begin{array}{c}\text { Very } \\
\text { satisfied }\end{array}$} \\
\hline $\mathbf{2 0 1 8}$ & 53 & 8 & 15 & 17 & 11 & 2 \\
\hline $\mathbf{2 0 1 9}$ & 153 & 11 & 27 & 67 & 45 & 3 \\
\hline $\mathbf{2 0 2 0}$ & 657 & 44 & 83 & 249 & 157 & 124 \\
\hline
\end{tabular}

As can be seen, in the case of question Q15 the situation is comparable to the previous questions, with the same upward trend, from an average of 2.70 to 3.01, reaching 3.36 in 2020.

Research hypothesis H2. The inhabitants and visitors of the city of Timișoara have a low level of satisfaction with the way in which the archaeological researches have been carried out so far is only partially validated. Even if in 2018 and in some cases in 2019 there are negative results, the year 2020 brings an increase in the level of satisfaction of respondents, which is positive, exceeding the average of 3 . The only aspect against which respondents still show a level of dissatisfaction remains the media coverage of preventive archaeological research, insufficient in the opinion of the subjects.

To follow the research hypothesis H.3 There is an association between the level of education of the subjects and the level of satisfaction with the preventive archaeological research in the city of Timisoara, for the years 2018 and 2019, the existence of an association between variables was not found, therefore the level of education of the subjects does not influence the level of satisfaction with any of the questions asked above, and our research hypothesis is not validated.

In 2020, however, performing the same non-parametric correlation tests we can see that there is an association between variables. Between the level of satisfaction regarding the way in which the archaeological research was carried out (Q5) and the variable Level of education there is a statistically significant correlation with a threshold of significance Sig <.001. However, the size of the effect is weak, the correlation coefficient being -.12, in other words we can speak of a slight association, inversely proportional, between variables (the higher the level of education, the lower the level of satisfaction). Between the level of satisfaction with the importance that the authorities give to archaeological research (Q10) and the variable Level of education there is a statistically significant correlation with a significance threshold Sig .001, but with a low correlation coefficient of .11 (as the level of education, thus increasing the level of satisfaction with the attitude of the authorities). A statistically significant correlation also appears in terms of satisfaction with the information provided by the media and the level of 
education. There is a significance threshold Sig .004, and a correlation coefficient -.105 . Even if the size of the effect is small, there is an inversely proportional relationship between the level of education and satisfaction with media involvement. The same situation arises in the relationship between the level of education and the degree of satisfaction with the existing information in the locations where archaeological research was conducted, to mark and inform the public about them (we record a significance threshold Sig .002 and a coefficient of correlation of -.11) or in the case of the relationship between the level of education and the degree of satisfaction with the way in which the archaeological objectives were restored and preserved (significance threshold of .001 and an effect size of -..11).

In all cases, it was found that there is a statistically confirmed link between the level of education and the degree of satisfaction of the subjects with the preventive archaeological research in the city of Timisoara, whether it is the way the research was conducted, the involvement of the authorities, the press, the appropriate signaling of the archeological objectives or their restoration and conservation. With one exception (involvement of authorities in the management of archaeological research), where we have a positive correlation between variables, in all other situations the correlation is weak but negative, the higher the level of education of the subjects, the lower their degree of satisfaction, which confirms our $\mathrm{H} 3$ research hypothesis.

A third objective of our approach was to establish the impact that preventive archaeological research has on the city, from the immediate implications (on pedestrian access, transport, public safety), to the long-term ones (on urban development), provided that this type of research is mandatory as a preamble to any local infrastructure development work. The research hypotheses we followed in our approach were: H4. Preventive archaeological research has the most consistent impact on local transport and H5. Preventive archaeological research can contribute to the development of urban tourism by restoring and capitalizing on archaeological objectives.

In order to validate these two hypotheses, questions Q6 - Q10 were introduced in the questionnaire: In your opinion, the archaeological research had implications ...; Consider that archaeological research can have positive consequences on ...; Consider that archaeological research is ...; What do you think should happen to the archeological objectives important for the culture and history of Timisoara?

Question Q6 concerns the consequences that respondents consider that preventive archaeological research has had, following the dimensions: public transport, pedestrian transport, public safety, public peace and cleanliness in the area.

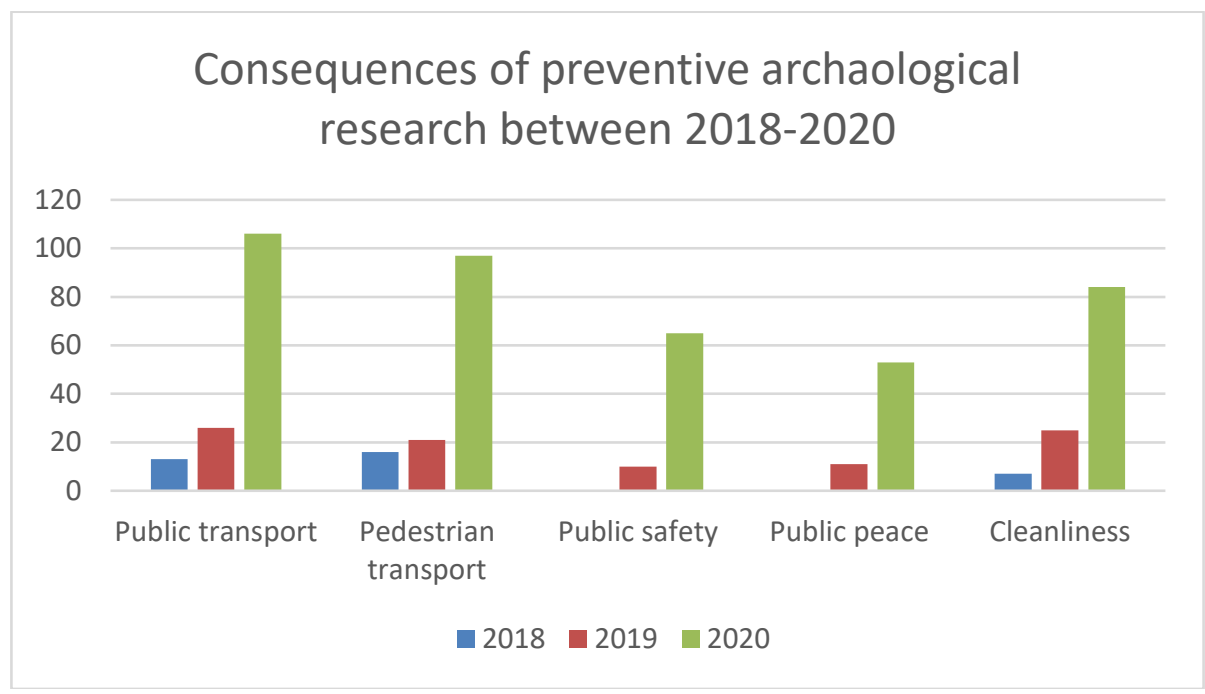


In 2018, 44 valid answers to this question were registered, out of 16 they supported the impact on pedestrian transport, followed by 13 public transport answers and 7 related to cleaning. The other options received no response. In the following year, public transport with 26 responses and cleanliness with 25 responses, followed by pedestrian transport with 21 responses were among the first choices of respondents, followed by public safety (11) and public peace (10 responses). In 2020, the subjects considered that preventive archaeological research had the most important consequences on public transport (106 responses), followed by pedestrian transport (97), cleanliness (84), public safety (65) and public peace (53).

The simple analysis of frequencies supports the validation of the research hypothesis H4. Preventive archaeological research has had the most consistent impact on local transport, often difficult, sometimes deviated, even blocked in that area during the archaeological research.

In order to see if the characteristics of the studied population (with reference to the area of residence and to the visit of the city) are dimensions that must be taken into account when researching the hypotheses, we decided to perform a crosstabulation for the two variables. The conclusions of the analysis showed that out of a total of 537 subjects (for all three years) 526 stated they had visited the city several times, 5 once and 6 never, and out of the 240 non-resident subjects in Timisoara, 224 stated they visited the city several times, 8 once and 8 never, so we can say that the area of residence is not a variable that can affect the results of our research, and most subjects know the city to a large extent (due to the fact that they visited him several times).

As for H5. Preventive archaeological research can contribute to the development of urban tourism by restoring and capitalizing on archaeological sites, most subjects appreciated the usefulness and need for preventive archaeological research, supporting the importance of restoring archaeological sites (2018: 59.6\% / 92.3\%; 2019: 79, 4\% / 79.5\%; 2020: 87.8\% / $84.3 \%$ ), which can contribute to:

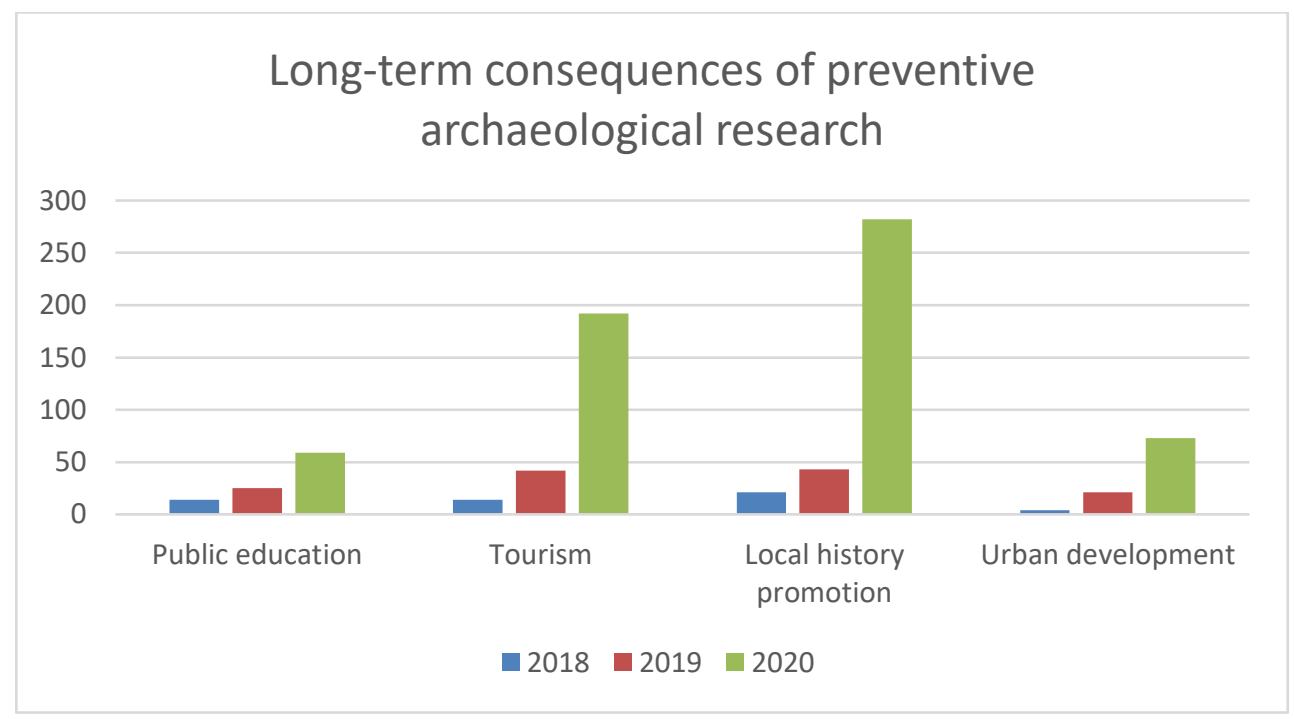

As can be seen, among the first options of the Timisoara public is the promotion of local history, followed by the development of tourism and public education. Preventive archeology can only contribute to urban development to a small extent in the opinion of our respondents. The hypothesis is validated in terms of the contribution of preventive archeology to the development of tourism, although, as can be seen, the public is more interested in the historicalnarrative, emotional and local memory, not the capitalization of archaeological potential for sustainable development of the city. 


\section{Conclusions}

Local communities and society as a whole have a public responsibility to protect cultural heritage. Increasingly, in recent years worldwide, cultural policies and cultural heritage are topics of interest to all of us. Sustainable development, like cultural heritage, are elements of public responsibility, and can become a mutual aid. Cultural heritage can be seen as an inexhaustible source of benefits for the community, and through policies that support the sustainable development of a geographical area or a community can be found the best way to capitalize on heritage.

The challenges that cities have to face change according to the expectations of the inhabitants of these cities. Also, the functions that cities perform are also constantly changing. In today's society, cities have to meet the educational and cultural needs of the local community. There is a need for an infrastructure that provides its inhabitants with means of relaxation and culture at the same time (Pelletier 2011, 17).

Cities that have a long history and still retain palpable traces of it are appreciated not only by its inhabitants but also by tourists who are attracted here by these traces of passage of time. All these fingerprints fall into the category of cultural heritage, which has more than once proved to be a life-saving solution in crisis situations for the city and its inhabitants.

In order to capitalize on the cultural heritage of our city, the whole community needs to see this potential that heritage has to contribute to the sustainable development of Timisoara, we, the inhabitants of this city need to see and protect this heritage and only in this way will tourists be able to see and be attracted by what we have to offer.

Cultural heritage is one of the basic pillars of cultural tourism, of that type of tourism that attracts more and more visitors every year and implicitly contributes financially to the economic development of a community, be it smaller or larger, as it is the case of Timisoara.

\section{REFERENCES}

Amirou, R. (2000), Imaginaire du tourisme culturel, Paris

Draşovean F., C. Feneșan, Al. Flutur, Al. Szentmiklosi, Georgeta El Susi, Zsuzsanna Kopeczny, Hedy M-Kiss, R. Șeptilici, Niculina Dinu (2007), Timișoara în amurgul evului mediu, Timișoara

Lebrun, N. (2013), Introduction: Fonctions urbaines et respiration patrimoniale de la ville, in Revue Géographique de l'Est, vol. 53 / 3-4, https://journals.openedition.org/rge/5126

Pelletier, Ph. (2011), Le Plan Bâtiment Grenelle, un chemin vertueux vers l'adaptation du patrimoine architectural, In Le patrimoine: un modèle de développement durable. Actes du colloque Paris, oct. 2010, 15-17

Szentmiklosi, Al. (2016), Stăvilarul fortificației de secolul al XVIII-lea din Timișoara- Piața 700. Punct museal în aer liber, in Banatica, XXVI, 433-444.

Venturini, E.J. (2011), Tourisme culturel et développement durable: le patrimoine au-dèla du spectacle, in Le patrimoine, moteur de développement. Actes du symposium de la XVIIème Assemblee Generale de l'ICOMOS, Paris, 567-574

Vernières, M. (2015), Le patrimoine: une ressource pour le développement, in Techniques Financières et Développement, nr. 118/1, 7-20 